\title{
Evaluation of the sterilization effect of a new mercury-free UVC light source
}

\author{
Han Gao ${ }^{\mathrm{a}, \mathrm{b}}$, Tongkuo Yuan ${ }^{\mathrm{b}, \mathrm{c}}$, Jian Zhao ${ }^{\mathrm{d}}$, Hongye Liu ${ }^{\mathrm{e}}$, Huancai Yin ${ }^{\mathrm{a}, \mathrm{b}, *}$ \\ a University of Science and Technology of China, Hefei, Anhui 230026 China \\ b CAS Key Lab of Bio-Medical Diagnostics, Suzhou Institute of Biomedical Engineering and Technology, \\ Chinese Academy of Sciences, Suzhou, Jiangsu 215163 China \\ c School of Life Sciences, Shanghai University, Shanghai 200433 China \\ d NovelUv Co., Ltd, Shanghai 201108 China \\ e Clinical Laboratory, Changchun Center Hospital, Jilin, Changchun 130051 China
}

*Corresponding author, e-mail: yinhc@sibet.ac.cn

Received 13 May 2019

Accepted 29 Oct 2019

\begin{abstract}
So far, short-wave UV produced by low-pressure mercury lamps has been widely applied in sterilization, wastewater treatment, and bioassays, which could be due to its low cost, high conversion efficiency, and small size. However, metal pollution is caused by the evitable releasing of mercury. In this study, a new mercury-free lamp was developed, which generated UV light by the electron beam excitation (EBE) of $\mathrm{YPO}_{4}: \mathrm{Bi}^{3+}$ under vacuum conditions. Such lamps emit light at $241 \mathrm{~nm}$ and possessed a photoelectric effect. Excellent sterilization effect was obtained in Candida albicans, Staphylococcus aureus, Pseudomonas aeruginosa, and Escherichia coli, in the absence of ozone. These effects positively correlated with the treatment distances and time. Furthermore, oxidative stress was found to play a major role in the sterilization process of our light sources, since no production of ozone was detected during each treatment. After all, EBE lamps could be a promising tool for sterilization, and our results provided the theoretical basis for its microorganism-killing effects.
\end{abstract}

KEYWORDS: UV, mercury-free lamp, electron beam excitation (EBE) UV lamp, ozone-free, oxidative stress

\section{INTRODUCTION}

Nowadays, UV light sources have been widely applied in industrial, agriculture, and medical fields, due to their fluorescent, biological, photochemical and photoelectric effects ${ }^{1}$. In particular, short-wave UV with wavelengths of 200-280 $\mathrm{nm}$ has been found useful in sterilization, wastewater treatment and biological detection ${ }^{2}$. Among them, low-pressure mercury lamps producing $254 \mathrm{~nm}$ UV light were mostly accepted, which could be due to their long lifetime, high photoelectric conversion efficiency, mature manufacturing process, and low cost ${ }^{3}$. Unfortunately, these lamps are being criticized for their releasing of mercury, which cause irreversible fatal damage to living organisms ${ }^{4}$. According to Minamata Treaty, mercury-containing UV light sources will be gradually replaced in 2020 . Thus more and more attentions are being paid on the development of mercury-free lamps.

The first developed light sources are mainly light-emitting diodes (LEDs), which have advantages of long life, small size, short start-up time, and no pollution ${ }^{5,6}$. Despite the long-term development, UVC-producing LEDs are limited by their complicated manufacturing process, high cost, low photoelectric conversion efficiency, and severe heat radiation ${ }^{7}$. In fact, the thermal emission cathode produced by LG Company, which are of the most matured manufactory techniques, only exhibits a low photoelectric conversion efficiency at $2 \%$. Hence an efficient, non-polluting, and long-lifetime UV sources are still in demand.

Based on the recent publications, UV light could be generated by electron beam excitation of phosphate, rare earth-doping material and $\mathrm{ZnO}^{8}$. With similar mechanisms, Oto et al developed new UV lamps by electron beam excitation of AlGaN quantum wells, which exhibited a high power of $100 \mathrm{~mW}$ at $240 \mathrm{~nm}^{9}$. Max Shatalov et al used AlGaN to develop a UV light source with a wavelength of $278 \mathrm{~nm}^{10}$. Compared with UV LED, EBE-UV light sources possessed simple production processes, no thermal effect, and high photoelectric conversion efficiency, thus exhibiting a promising application 


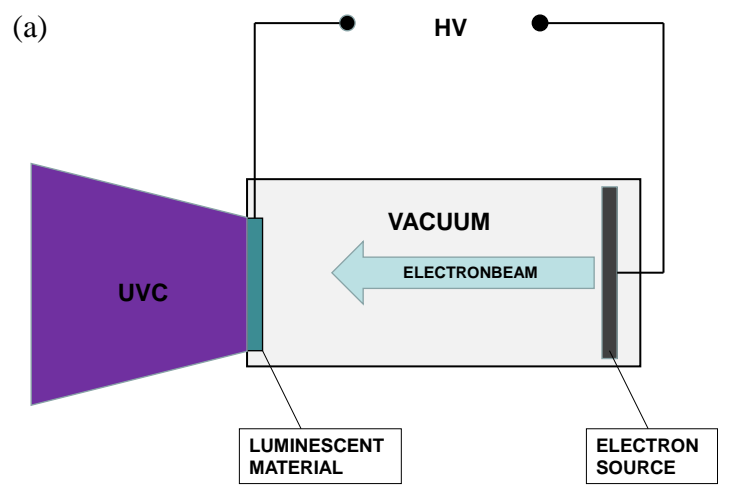

(b)

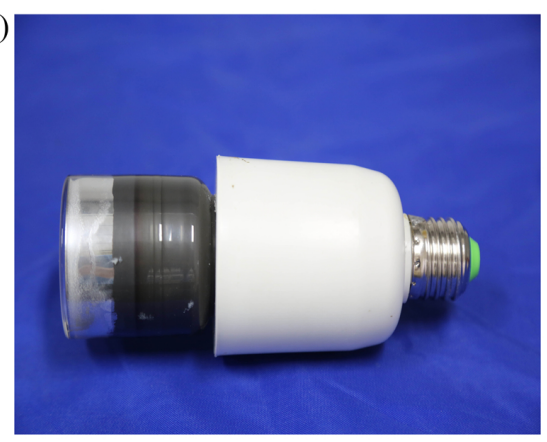

Fig. 1 (a) Schematic diagram of $\mathrm{YPO}_{4}: \mathrm{Bi}^{3+}$ EBE-UV lamp, $\mathrm{HV}=$ high voltage; (b) UV lamp body diagram.

prospect $^{11,12}$.

In this study, a small sterilization device was produced with an EBE-UV light source. After characterization of photoelectric conversion efficiency and wavelength, the sterilization properties of this lamp were tested with four microorganisms, including Candida albicans, Staphylococcus aureus, Pseudomonas aeruginosa, and Escherichia coli. After then, the main sterilization mechanism of this lamp was detected, to provide the basis for its application in sterilization.

\section{MATERIALS AND METHODS}

\section{EBE-UV characterization}

The EBE-UV light was produced by electron beam excitation on $\mathrm{YPO}_{4}: \mathrm{Bi}^{3+}$, and the cold cathode is protected by vacuum environment ${ }^{4}$. In brief, the electrons hit the matrix of $\mathrm{YO}_{4}: \mathrm{Bi}^{3+}$, causes energy transfer, and excites the fluorescence. With specific optical filter, the wavelength of UV would be limited around $241 \mathrm{~nm}$. By DC Ammeter and Voltmeter, the input power of the UV lamp is $1.3 \mathrm{~W}$, and output power is determined to be $52.13 \mathrm{~mW}$. The photoelectric conversion rate $\eta$ is calculated according to $\eta=\left(P_{\text {light }} / P_{\mathrm{e}}\right) \times 100 \%$, where $P_{\text {light }}$ and $P_{\mathrm{e}}$ are (a)

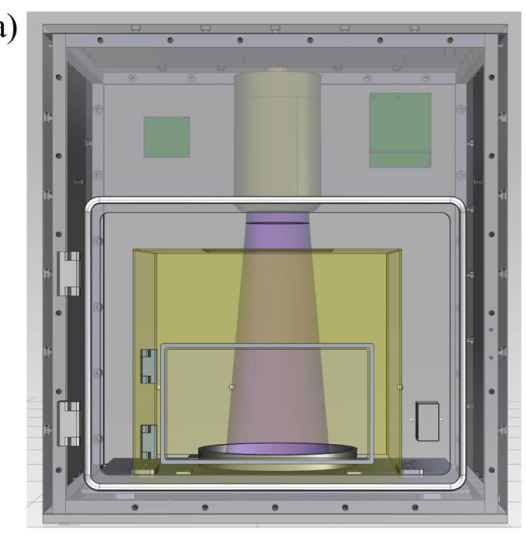

(b)

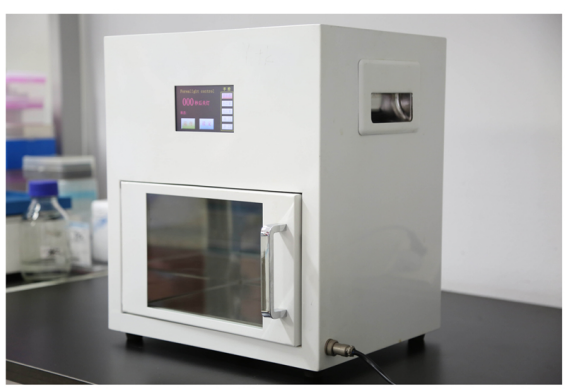

Fig. 2 (a) Schematic diagram of sterilization device; (b) physical map of the equipment.

the electrical and optical powers, respectively. After calculation, $\eta$ should be $4.01 \%$.

The schematic and digital illustrations of the lamp are shown in Fig. 1. Its emission spectra were evaluated by a UV spectrometer (Gentec, Florida, USA) in a wavelength range of $200-360 \mathrm{~nm}$. Irradiance power of EBE-UV was measured using a PH100-SiUV Probe accumulated UV meter (Ushio Inc., Japan), after the switch was turned on, the UV meter was set as zero first. Then the irradiance power was randomly detected at 5 different positions of the same height to calculate the average value.

\section{Sterilization device}

To test the efficiency of UV light source, a small sterilizer with adjustable distance and treatment time was designed. The structure is shown in Fig. 2.

The sterilizer consists of two parts: tank and shell. The tank was made of corrosion-resistant stainless-steel material (ISO11), with a hole in the upper field. The light sources located inside the shell, right on the upper of the tank holes. The lighting time, interval time, and automatic light-off could be controlled automatically. A transparent viewing window is present on the outer shell, to observe 
the entire illumination process. Tin foil was used to cover the shading treatment on the observation window, to avoid the light resurrection during UV treatment. Finally, adjust the distances between the light sources and the plane of the lowest-end plates, to determine the sterilization characteristics.

\section{Culture of microorganisms}

C. albicans (ATCC10231), S. aureus (ATCC25923), P. aeruginosa (ATCC9027), and E. coli (ATCC25922) obtained from American Type Culture Collection, were cultured at $37^{\circ} \mathrm{C}$ in tryptic soy broth ( $\mathrm{pH} 7.2$, BD Diagnosis Systems, Sparks, MD) ${ }^{13-15}$. All the bacteria and yeast kept on a rotary shaker at $220 \mathrm{rpm}$ were cultivated for $8 \mathrm{~h}$. The concentration of cells was $10^{9} \mathrm{CFU} / \mathrm{ml}$ as assessed by $600 \mathrm{~nm}$ absorption.

\section{Evaluation of sterilization effect}

Microorganisms, including yeast (C. albicans), Gram-positive bacteria ( $S$. aureus), and Gramnegative bacteria ( $E$. coli and $P$. aeruginosa), were used to evaluate the sterilization effect of EBEUV. After reaching the set concentrations of $10^{9}$ $\mathrm{CFU} / \mathrm{ml}$, the four strains of microorganisms were diluted by $1: 10000^{16}$. $100 \mu \mathrm{l}$ of dilution was cultured on the solid nutrient agar medium, and then immediately placed in the sterilization device. All agar media were treated with $\mathrm{UV}$ at $15 \mathrm{~cm}$ from the UV light source at $37^{\circ} \mathrm{C}$. According to the tolerance of each strain, different time gradients were used for $C$. albicans $(0.0,1.0,2.0,3.0$, and $4.0 \mathrm{~min}$ ), P. aeruginosa $(0.0,1.0,1.5,2.0$, and $2.5 \mathrm{~min})$, $S$. aureus $(0.0,0.5,1.0,1.5,2.0,2.5,3.0$, and $3.5 \mathrm{~min}$ ), and E. coli (0.0, 5.0, 10.0, 15.0, 20.0, 25.0, $30.0,35.0$, and $40.0 \mathrm{~s})$. Then the survived colonies were counted and compared with untreated control. The differences were divided by the total colonies, and the results were defined as the disappearance rate. The obtained values were plotted against the irradiation dose $\left(K,\left(\mathrm{~mW} . \mathrm{s} / \mathrm{cm}^{2}\right)\right)$ of UV, which was calculated as $K=I \times T / 10^{3}$, where $I$ and $T$ are the irradiation intensity $\left(\mu \mathrm{W} / \mathrm{cm}^{2}\right)$ and irradiation time (s), respectively. To prevent cells from reactivation, the processes of UV treatment and cultivating were shaded away from light.

\section{Intracellular ROS assay}

After sterilization, the microorganisms on the plate were scraped off with $1.0 \mathrm{ml}$ PBS. About $100 \mu \mathrm{l}$ of the treated suspensions were taken out for total number counting, and the remaining suspensions were collected into $1.5 \mathrm{ml}$ eppondorf tubes (EP), to measure intracellular ROS with commercial Kits (Beyotime, China) ${ }^{17} .10 \mu \mathrm{m} \mathrm{2,7-}$ dichlorodihydrofluorescein diacetate (DCFH-DA) was added to the treated suspensions and incubated for $20 \mathrm{~min}$ at $37^{\circ} \mathrm{C}$. Then the cells were washed and suspended in $1.0 \mathrm{ml}$ of PBS. The pictures of accumulated $2^{\prime}, 7^{\prime}$-dichlorofluorescein (DCF) inside cells were taken with a digital camera (Olympus Corporation, Tokyo) and a Zeiss axiophot fluorescence microscopy (Carl Zeiss, Oberkochen, Germany) with a green filter. After then, the fluorescence of suspension was detected with a Multi-Mode microplate Reader (BioTek, US) using an excitation/emission wavelength of $488 / 525 \mathrm{~nm}$. Relative fluorescence intensity (RFI) of the intracellular ROS level was normalized to the total number of microorganism ${ }^{18}$, and then expressed as the fold increase of control group.

$$
\mathrm{RFI}=\frac{\mathrm{DCF}_{\mathrm{EX}} /(1-\text { Disappearance } \%)_{\text {D }}}{\mathrm{DCF}_{\text {Control }}},
$$

where $\mathrm{DCF}_{\mathrm{EX}}$ and $\mathrm{DCF}_{\mathrm{Control}}$ are the detected fluorescence of the treated groups and the control group, respectively.

\section{Ozone content detection}

The light resource of the UV sterilizer was fixed at $15 \mathrm{~cm}$ from the bottom of the plate. Since all the microorganisms died after 20 min irradiation. The ozone production was detected after then. Ozone instrument (JSA8-O3, Shenzhen, China) was used to detect the ozone content at 6 random points to obtain an average value. The enclosed space of this device is $15 \mathrm{~cm}$ in height, $23 \mathrm{~cm}$ in length, $10 \mathrm{~cm}$ in width. The total volume is about $3.45 \mathrm{l}$. As a positive control, the ozone produced by an ordinary $254 \mathrm{~nm}$ lamp (TUV, $8 \mathrm{~W}$, Philips) was detected in the same condition, and the results indicated a $2.7 \mathrm{ppm}$ production of ozone.

\section{DNA damage analysis}

After UVC irradiation for indicated time, the four microorganisms were collected and extracted for their DNA with a commercial kit. The degree of DNA damage was determined by the alkaline version of the Comet Assay (single-cell gel electrophoresis SCGE) as described by Lanier et $\mathrm{al}^{19}$. The irradiation time was selected for each microorganism with the occurrence of significant death. The obtained comets were visualized with a fluorescent microscope (Carl Zeiss, Oberkochen, Germany) at $40 \times$ magnification (Achroplan and ECPlan-Neofluar objectives) with the red filter (excitation $546 \mathrm{~nm}$ and 


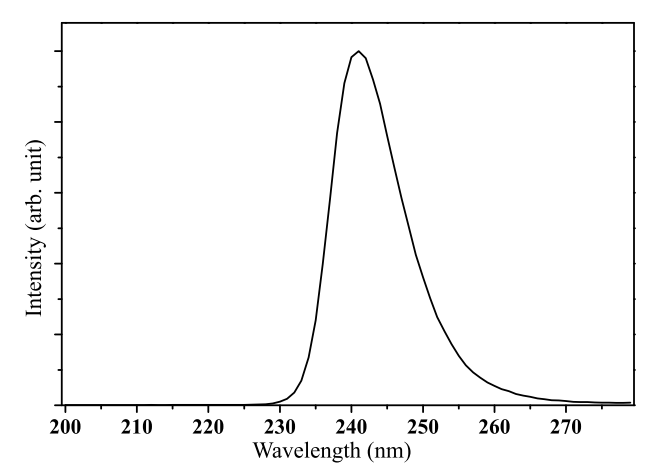

Fig. 3 Emission spectra of $\mathrm{YPO}_{4}: \mathrm{Bi}^{3+}$ EBE-UV lamp.

Table 1 Radiation intensity at different distance (DIST) from the lighting tube.

\begin{tabular}{lccccc}
\hline DIST $/ \mathrm{cm}$ & 3 & 6 & 9 & 12 & 15 \\
Irradiance $\left(\mu \mathrm{W} / \mathrm{cm}^{2}\right)$ & 651.1 & 280.6 & 139.1 & 84.2 & 55.5 \\
\hline
\end{tabular}

emission $590 \mathrm{~nm}$ ). The obtained images were analysed using AxioVision software version 4.7.2 (Carl Zeiss, Oberkochen, Germany).

\section{Statistical analysis}

All data represent here are mean \pm SD of three independent experiments with each in triplicate $(n=9)$. Statistical analysis was performed using SPSS Statistic 15.0 Software (SPSS Inc., Chicago, Illinois, USA). Comparisons were conducted between control and treated groups with student's $t$-test, ${ }^{*} p<0.05$ was considered significant.

\section{RESULTS}

\section{Characterization of EBE-UV light sources}

The diameter of the front-edge of UV light source is $50 \mathrm{~mm}$, and the length of the whole light source is $155 \mathrm{~mm}$. The emission spectrum is shown in Fig. 3, which indicates a core wavelength of $241 \mathrm{~nm}$ with a half-peak width of $15 \mathrm{~nm}$. The photoelectric conversion efficiency was determined to be $4.01 \%$. After 1000-h operation, the photoelectric conversion efficiency will be reduced by about $75 \%$. The irradiance at different distances from the light source is shown in Table 1, which decreases gradually with the increase in distance.

\section{Evaluation of sterilization effect}

To evaluate the microorganism-killing effect of deep-UV light, four strains of microorganisms (yeast, Gram-positive and Gram-negative bacteria) were irradiated with $241 \mathrm{~nm} \mathrm{UV}$ at different doses.
It could be seen that the sterilization efficiency of this EBE-UV light was dose-dependent, and all the microorganisms could be killed under the irradiation lower than $66.6 \mathrm{~mW} . \mathrm{s} / \mathrm{cm}^{2}$. As shown in Fig. 4a, the most tolerant microorganism was $C$. albicans, while $E$. coli was the most easily killed bacteria (Fig. 4d). The tolerance of $P$ aeruginosa and $S$. aureus was found to be between $C$. albicans and E. coli (Fig. 4bc).

\section{Sterilization mechanism}

The changes of ROS curve in the four microorganisms after UV treatment were shown in Fig. 5a. As the irradiation time and dose increase, the levels of ROS increase to different degrees for each microorganism. To more intuitively show the effect of irradiation on cells, the fluorescence intensity of DCF in cells was photographed by fluorescence microscopy in the experiment, and the results were shown in the following Fig. 5b, which became brighter with the increase of treatment time. Surprisingly, no production of ozone was detected during the treatment of EBE-UV lights, as the data kept below zero during the detection. In addition, significant DNA damages were noticed after UVC irradiation, as DNA migration exhibited an obvious comet style (Fig. 6 and Table 2).

\section{DISCUSSION}

With the development of science and technology, the demands for human health continue to increase. As an important environmental pollutant, mercury is posing a huge threat to human health due to their extensive applications in the industry ${ }^{20}$. On 19 January 2013, the United Nations Environment Programme adopted Minamata Convention, to reduce the releasing of mercury in the world ${ }^{21}$. For the UV light sources, the convention clearly states that after 2020, low-cost mercury lamps will be unavailable. Hence all countries are developing high-efficiency and mercury-free UV light sources, to occupy a huge market including lighting, sterilization, and wastewater treatment.

In this study, a new sterilization device was constructed with new mercury-free UV sources. The lamp has a maximum emission wavelength of $241 \mathrm{~nm}$ with a half-width of $15 \mathrm{~nm}$. The photoelectric conversion efficiency was calculated to be $4 \%$. After improvement on the matrix, much higher photoelectric conversion efficiency of even $12 \%$ could be achieved, which is much higher than LG's commercial products (data to be published). 

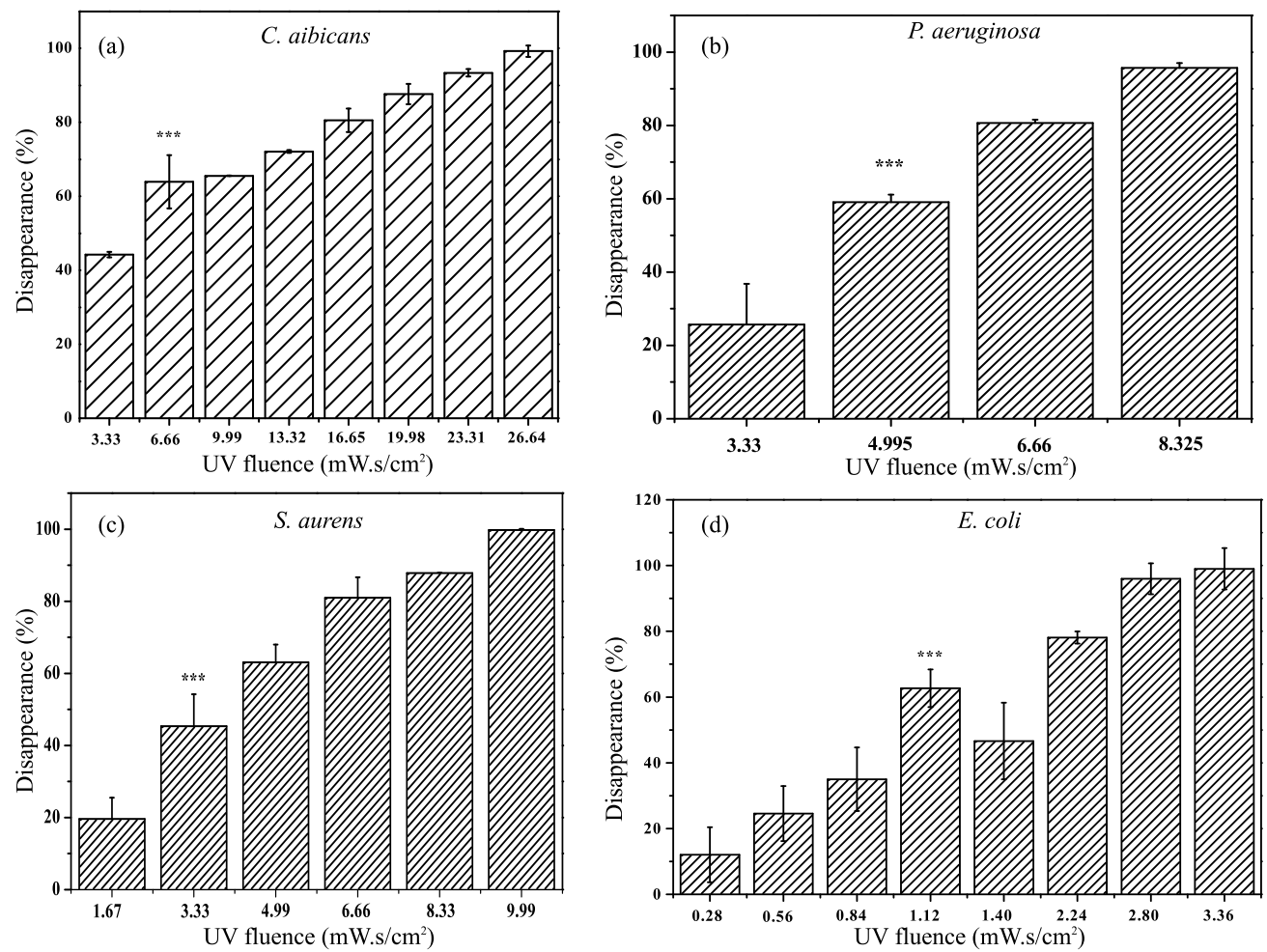

Fig. 4 The sterilization efficiency at $241 \mathrm{~nm}$ was examined by disappearance of (a) C. albicans, (b) P. aeruginosa, (c) S. aureus, and (d) E. coli. Data are expressed as means \pm SD of 3 samples, $* * * p<0.001$ compared with untreated control.
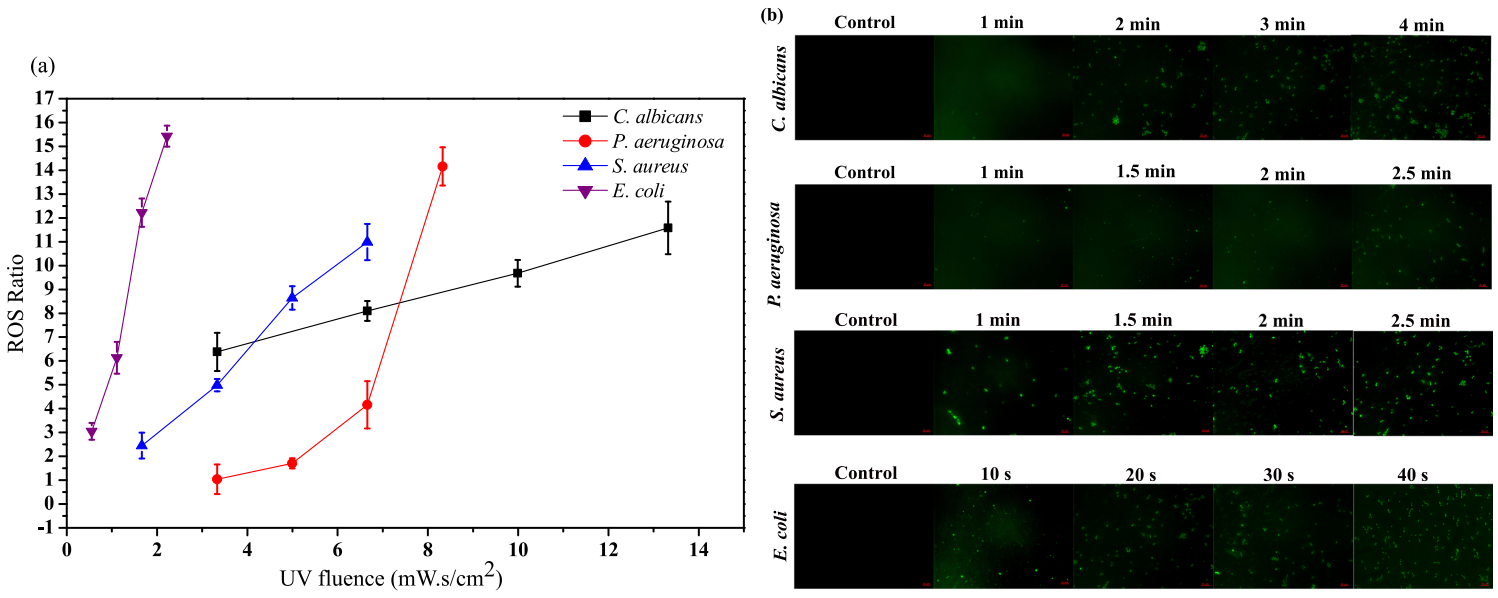

Fig. 5 (a) Intracellular ROS concentration after the treatment with $241 \mathrm{~nm}$ EBE-UV lamp in yeast, Gram-positive,

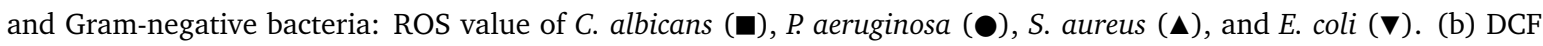
fluorescence produced by bacteria with fluorescence microscope.

In the previous reports, the effective radiation power of conventional sterilization lamp $(254 \mathrm{~nm})$ was $150 \mathrm{~mJ} / \mathrm{cm}^{2}\left(1.5 \times 10^{3} \mathrm{~mW} \cdot \mathrm{s} / \mathrm{cm}^{2}\right)$, which could kill C. albicans up to $10^{-5} \mathrm{CFU} / \mathrm{ml}^{22}$. The dose used by Mohr $\mathrm{H}$ and Gravemann $\mathrm{U}$ was even higher,
$300 \mathrm{~mJ} / \mathrm{cm}^{2}\left(3.0 \times 10^{3} \mathrm{~mW} \cdot \mathrm{s} / \mathrm{cm}^{2}\right)$ to inactivate 10 bacteria species in platelet concentrates ${ }^{23}$. On the other hand, Dotson et al used doses from 0.1$0.2 \mathrm{~J} / \mathrm{cm}^{2}\left(1.0 \times 10^{3}\right.$ to $2.0 \times 10^{3} \mathrm{~mW} \cdot \mathrm{s} / \mathrm{cm}^{2)}$ for drinking water disinfection ${ }^{24}$. All these irradiation 
Table 2 Analytical results of comet assay.

\begin{tabular}{lccccccc}
\hline Sample & $\begin{array}{c}\text { L-head } \\
(\mu \mathrm{m})\end{array}$ & $\begin{array}{c}\text { L-tail } \\
(\mu \mathrm{m})\end{array}$ & $\begin{array}{c}\text { L-comet } \\
(\mu \mathrm{m})\end{array}$ & $\begin{array}{c}\text { Head-DNA } \\
(\%)\end{array}$ & $\begin{array}{c}\text { Tail-DNA } \\
(\%)\end{array}$ & $\begin{array}{c}\text { Tail } \\
\text { moment }\end{array}$ & $\begin{array}{c}\text { Olivetail } \\
\text { moment }\end{array}$ \\
\hline C. albicans 0 $\mathrm{min}$ & $27.0 \pm 2.4$ & $4.3 \pm 0.6$ & $31.4 \pm 3.3$ & $97.53 \pm 3.96$ & $2.46 \pm 0.85$ & $0.09 \pm 0.02$ & $0.32 \pm 0.02$ \\
C. albicans 1 min & $31.6 \pm 3.8$ & $37.7 \pm 4.0^{*}$ & $69.3 \pm 9.8^{*}$ & $73.33 \pm 5.95$ & $26.66 \pm 3.05^{*}$ & $8.93 \pm 2.08^{*}$ & $9.20 \pm 2.92^{*}$ \\
C. albicans $3 \mathrm{~min}$ & $27.3 \pm 3.6$ & $33.5 \pm 5.5^{*}$ & $60.8 \pm 4.2$ & $73.54 \pm 8.57$ & $26.45 \pm 3.43^{*}$ & $10.72 \pm 1.99^{*}$ & $4.03 \pm 0.12^{*}$ \\
P. aeruginosa 0 min & $25.7 \pm 3.4$ & $3.0 \pm 1.1$ & $28.7 \pm 3.7$ & $99.95 \pm 8.78$ & $0.04 \pm 0.02$ & $0.02 \pm 0.003$ & $0.01 \pm 0.09$ \\
P. aeruginosa 1 min & $23.9 \pm 3.6$ & $21.7 \pm 4.8^{*}$ & $45.7 \pm 3.3$ & $79.37 \pm 6.99$ & $20.62 \pm 3.01^{*}$ & $4.33 \pm 2.02^{*}$ & $3.93 \pm 1.33^{*}$ \\
P. aeruginosa 2 min & $19.7 \pm 3.9$ & $29.8 \pm 6.2^{*}$ & $49.5 \pm 4.8$ & $38.10 \pm 4.22^{*}$ & $61.89 \pm 5.78^{*}$ & $17.95 \pm 2.04^{*}$ & $9.98 \pm 1.96^{*}$ \\
S. aureu 0 min & $27.1 \pm 2.4$ & $3.7 \pm 1.6$ & $30.7 \pm 7.6$ & $99.93 \pm 12.55$ & $0.06 \pm 0.45$ & $0.009 \pm 0.0003$ & $0.009 \pm 0.0003$ \\
S. aureu 0.5 min & $26.0 \pm 8.8$ & $18.7 \pm 7.3^{*}$ & $44.7 \pm 6.9$ & $84.28 \pm 7.98$ & $15.71 \pm 4.02^{*}$ & $2.82 \pm 1.78^{*}$ & $2.73 \pm 1.71^{*}$ \\
S. aureu 2 min & $25.6 \pm 5.8$ & $50.9 \pm 7.4^{*}$ & $76.5 \pm 9.7^{*}$ & $63.83 \pm 4.72$ & $36.16 \pm 3.28^{*}$ & $18.08 \pm 9.14^{*}$ & $12.81 \pm 7.65^{*}$ \\
E. coli 0 min & $23.2 \pm 3.3$ & $4.0 \pm 1.4$ & $27.2 \pm 4.1$ & $99.97 \pm 9.38$ & $0.02 \pm 0.01$ & $0.007 \pm 0.003$ & $0.003 \pm 0.002$ \\
E. coli 10 s & $19.4 \pm 4.8$ & $3.9 \pm 2.4$ & $23.4 \pm 8.6$ & $99.92 \pm 27.72$ & $0.07 \pm 0.02$ & $0.002 \pm 0.001$ & $0.007 \pm 0.006$ \\
E. coli 40 s & $19.4 \pm 4.0$ & $9.6 \pm 2.1^{*}$ & $28.9 \pm 5.1$ & $74.16 \pm 8.23$ & $25.83 \pm 7.77^{*}$ & $2.32 \pm 1.54^{*}$ & $2.56 \pm 1.35^{*}$ \\
\hline
\end{tabular}

" $p<0.05$ versus control.
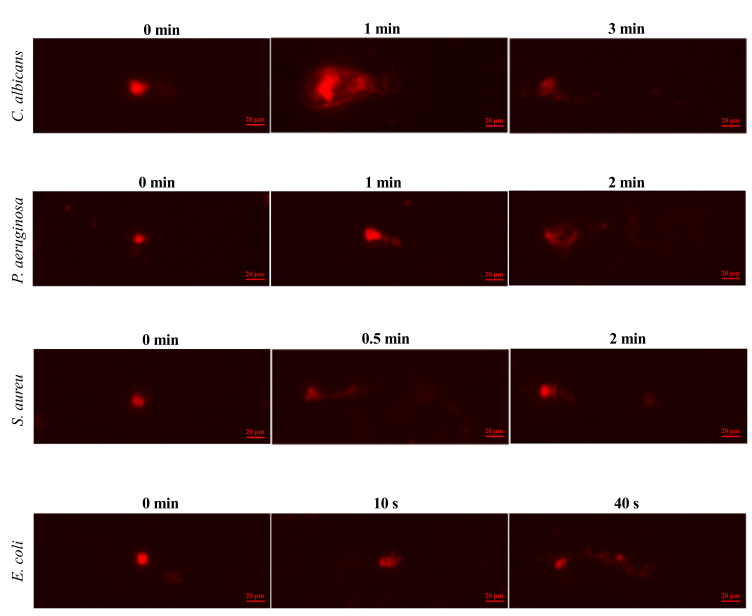

Fig. 6 Representative comet assay images for the four strains: C. albicans, P. aeruginosa, S. aureus, and E. coli after the treatment with EBE-UV light.

doses were much higher than that in this experiment, where the new UV sources killed all the four microorganisms after irradiation of $20 \mathrm{~min}$ and the dose reached $66.6 \mathrm{~mW} \cdot \mathrm{s} / \mathrm{cm}^{2}$. Such phenomenon could be due to the narrow spectral peak at $241 \mathrm{~nm}$ compared with broad-spectrum of traditional lamps.

According to literature, DNA damage, ROS effects, and production of ozone could be the reasons of UV sterilization. In this experiment, ROS effects and DNA damages have been found in this experiment (Fig. 5 and Fig. 6). However, no ozone was detected after the irradiation of UV lights for 20 min. Such phenomenon could be occurred on the fact that the emission spectrum of EBE lights does not contain $185 \mathrm{~nm}$, which ionizes the air to generate ozone ${ }^{25}$. Although ozone can be useful for sterilization, it has strong oxidizing properties, which can cause ageing of equipment and is not suitable for human environment ${ }^{26,27}$. In this respect, the application of new UV light sources could be advantageous.

\section{CONCLUSION}

In this paper, a novel sterilization device was constructed with EBE-UV light sources, which generated UV light with an electron beam to excite $\mathrm{YPO}_{4}: \mathrm{Bi}^{3+}$ material. This device had a narrow emission peak $(241 \pm 25 \mathrm{~nm})$, high photoelectric conversion efficiency (4.01\%), environmental friendliness (without mercury) and low cost (around $0.5 \$ / \mathrm{mW}$ ). This device exhibited an excellent sensitization effect at $15 \mathrm{~cm}$ from the light source, with oxidative stress as the major mechanism. Hence it has great application prospects for the surface sterilization of objects.

Acknowledgements: This work was supported by grants from National Science and Technology Major Project of China (2017ZX10302301-003) and National Key R\&D Programme of China (2017YFF0108600 \& 2017YFC0110400).

\section{REFERENCES}

1. Rozhansky IV, Zakheim DA (2006) Analysis of dependence of electroluminescence efficiency of AIInGaN LED heterostructures on pumping. Phys Status Solidi C 3, 2160-2164.

2. Gayan E, Serrano MJ, Pagan R, Alvarez I, Condon $S$ (2015) Environmental and biological factors influencing the UV-C resistance of Listeria monocytogenes. Food Microbiol 46, 246-253. 
3. Chen J, Loeb S, Kim JH (2017) LED revolution: fundamentals and prospects for UV disinfection applications. Environ Sci Water Res Technol 3, 188-202.

4. Yoo ST, Hong JH, Kang JS, Park KC (2018) Deepultraviolet light source with a carbon nanotube coldcathode electron beam. $J$ Vac Sci Technol B 36, ID $02 \mathrm{C} 103$.

5. De Volder MF, Tawfick SH, Baughman RH, Hart AJ (2013) Carbon nanotubes: present and future commercial applications. Science 339, 535-539.

6. Hirayama H, Maeda N, Fujikawa S, Toyoda S, Kamata N (2014) Recent progress and future prospects of AlGaN-based high-efficiency deep-ultraviolet lightemitting diodes. Jpn J Appl Phys 53, ID 100209.

7. Song K, Mohseni M, Taghipour F (2016) Application of ultraviolet light-emitting diodes (UV-LEDs) for water disinfection: a review. Water Res 94, 341-349.

8. Ge CQ, Xie CS, Hu ML, Gui YH, Bai ZK, Zeng DW (2007) Structural characteristics and UV-light enhanced gas sensitivity of La-doped $\mathrm{ZnO}$ nanoparticles. Mater Sci Eng B 141, 43-48.

9. Oto T, Banal RG, Kataoka K, Funato M, Kawakami Y (2010) $100 \mathrm{~mW}$ deep-ultraviolet emission from aluminium-nitride-based quantum wells pumped by an electron beam. Nat Photonics 4, 767-770.

10. Shatalov M, Sun WH, Lunev A, Hu XH, Dobrinsky A, Bilenko Y, Yang JW, Shur M, et al (2012) AlGaN deep-ultraviolet light-emitting diodes with external quantum efficiency above 10\%. Appl Phys Express 5, ID 082101.

11. Watanabe $K$, Taniguchi $T$, Niiyama $T$, Miya $K$, Taniguchi M (2009) Far-ultraviolet plane-emission handheld device based on hexagonal boron nitride. Nat Photonics 3, 591-594.

12. Ichikawa N, Ikeda K, Honda Y, Taketomi H, Kawai K, Suzuki T (2016) Development of a UV light source using Pr:LuAG thin film pumped by electron beam. Electron Commun Jpn 99, 33-39.

13. Sousa AM, Machado I, Nicolau A, Pereira MO (2013) Improvements on colony morphology identification towards bacterial profiling. J Microbiol Methods 95, 327-335.

14. Barboza DD, Martins LCA, Correa TQ (2018) Photodynamic inactivation of Staphylococcus aureus and Escherichia coli using a new bacteriochlorin as photosensitizer. In: Kessel DH, Hasan T (eds) Optical Methods for Tumor Treatment and Detection - Mechanisms and Techniques in Photodynamic Therapy 27th, California, USA.

15. Narita K, Asano K, Morimoto Y, Igarashi T, Hamblin MR, Dai TH, Nakane A (2018) Disinfection and healing effects of 222-nm UVC light on methicillinresistant Staphylococcus aureus infection in mouse wounds. J Photochem Photobiol B 178, 10-18.

16. Bagattini M, Buonocore R, Giannouli M, Mattiacci
D, Bellopede R, Grimaldi N, Nardone A, Zarrilli R, et al (2015) Effect of treatment with an overheated dry-saturated steam vapour disinfection system on multidrug and extensively drug-resistant nosocomial pathogens and comparison with sodium hypochlorite activity. BMC Res Notes 8, ID 551.

17. Li JH, Wang G, Zhu HQ, Zhang $M$, Zheng XH, Di ZF, Liu XY, Wang X (2014) Antibacterial activity of large-area monolayer graphene film manipulated by charge transfer. Sci Rep 4, ID 4359.

18. Soares SS, Gutierrez-Merino C, Aureliano M (2007) Mitochondria as a target for decavanadate toxicity in sparus aurata heart. Aquat Toxicol 83, 1-9.

19. Lanier C, Bernard F, Dumez S, Leclercq J, Lemiere S, Vandenbulcke F, Nesslany F, Platel A,et al (2016) Combined effect of $\mathrm{Cd}$ and $\mathrm{Pb}$ spiked field soils on bioaccumulation, DNA damage, and peroxidase activities in trifolium repens. Environ Sci Pollut Res 23, 1755-1767.

20. Beck SE, Ryu H, Boczek LA, Cashdollar JL, Jeanis KM, Rosenblum JS, Lawal OR, Linden KG (2017) Evaluating UV-C LED disinfection performance and investigating potential dual-wavelength synergy. Water Res 109, 207-216.

21. Gibb H, O'Leary KG (2014) Mercury exposure and health impacts among individuals in the artisanal and small-scale gold mining community: a comprehensive review. Environ Health Perspect 122, 667-672.

22. Buonanno M, Stanislauskas M, Ponnaiya B, Bigelow AW, Randers-Pehrson G, Xu Y, Shuryak I, Smilenov L, et al (2013) 207-nm UV light - a promising tool for safe low-cost reduction of surgical site infections. I: in vitro studies. PLoS One 8, ID e76968.

23. Mohr H, Gravemann U, Bayer A, Mueller TH (2009) Sterilization of platelet concentrates at production scale by irradiation with short-wave ultraviolet light. Transfusion 49, 1956-1963.

24. Dotson AO, Rodriguez CE, Linden KG (2012) UV disinfection implementation status in US water treatment plants. J Am Water Works Assoc 104, 318-324.

25. Szeto W, Li JT, Huang HB, Leung DYC (2018) $\mathrm{VUV} / \mathrm{TiO}_{2}$ photocatalytic oxidation process of methyl orange and simultaneous utilization of the lampgenerated ozone. Chem Eng Sci 177, 380-390.

26. Galante R, Ghisleni D, Paradiso P, Alves VD, Pinto TJA, Colaco R, Serro AP (2017) Sterilization of silicone-based hydrogels for biomedical application using ozone gas: comparison with conventional techniques. Mater Sci Eng C 78, 389-397.

27. Wang YZ, Wang HY, Li XS, Liu DX, Jiang YF, Sun $\mathrm{ZH}$ (2013) $\mathrm{O}_{3} / \mathrm{UV}$ synergistic aging of polyester polyurethane film modified by composite UV absorber. J Nanomater 2013, ID 169405. 